\title{
Escutar o leitor: \\ leitura e subjetividade em biografias e depoimentos de escritores
}

LIMA, Sheila Oliveira ${ }^{1}$

\section{RESUMO}

Nos últimos anos, realizamos projetos de pesquisa e extensão com a perspectiva de melhor compreender o fenômeno da leitura e a formação de leitores promovida no ambiente escolar. Atualmente, desenvolvemos novo projeto cujo objetivo é realizar uma escuta de depoimentos de escritores sobre seus processos de formação leitora. Com isso, busca-se identificar elementos que possam compor novas formulações no âmbito das metodologias para a formação do leitor. Ao final, trazemos uma pequena amostra de escuta de três relatos autobiográficos em que comparece a relação afetiva no processo de formação leitora dos escritores Manuel Bandeira, José Saramago e Cristóvão Tezza.

Leitura. Escritores. Autobiografia. Escuta.

\section{Listening to the Reader: reading and subjectivity in biographies and writer's testimonies}

\begin{abstract}
In recent years we have carried out research and extension projects with the perspective of better understanding the phenomenon of reading and the formation of readers promoted in school environment. Currently we have developed a new project whose objective is to listen to writers' testimonies about their reading formation processes. Thus we seek to identify elements that may compose new formulations within the scope of methodologies for the reader formation. At the end, it presents a small listening sample of three autobiographical reports in comparison to the affective relationship in the process of reading formation of writers Manuel Bandeira, José Saramago and Cristóvão Tezza.
\end{abstract}

Reading. Writers. Autobiography. Listening.

\footnotetext{
${ }^{1}$ Doutora em Educação (USP), Professora do Departamento de Letras Vernáculas e Clássicas do $\mathrm{CCH}$ da Universidade Estadual de Londrina. Mestre em Teoria Literária e Literatura Comparada. E-mail: sheilaol@uol.com.br. Lattes: http://lattes.cnpq.br/7552098448712248. ORCID: https://orcid.org/0000-0002-0993-8228.
} 


\section{Ascoltare il Lettore: lettura e soggettività nelle biografie e testimonianze dello scrittore}

\section{RIASSUNTO}

Negli ultimi anni abbiamo condotto ricerche con la prospettiva di una migliore comprensione del fenomeno della lettura e della formazione dei lettori promossi nell'ambiente scolastico. Attualmente stiamo sviluppando un nuovo progetto il cui obiettivo è ascoltare le testimonianze degli scrittori sui loro processi di educazione alla lettura. Pertanto, cerchiamo di identificare elementi che possano comporre nuove formulazioni nell'ambito delle metodologie per la formazione del lettore. Alla fine, portiamo un piccolo esempio di ascolto di tre rapporti autobiografici che mostrano la relazione affettiva nel processo di formazione della lettura degli scrittori Manuel Bandeira, José Saramago e Cristóvão Tezza.

Lettura. Scrittori. Autobiografia. La escolta.

\section{Escucha al lector: lectura y subjetividad en biografías y testimonios de escritores}

\section{RESUMEN}

En los últimos años, hemos realizado proyectos de investigación y extensión con la perspectiva de comprender mejor el fenómeno de la lectura y la formación de lectores promovidos en el entorno escolar. Actualmente estamos desarrollando un nuevo proyecto cuyo objetivo es escuchar los testimonios de los escritores sobre sus procesos de educación en lectura. Por lo tanto, buscamos identificar elementos que puedan componer nuevas formulaciones dentro del alcance de las metodologías para la formación del lector. Al final, traemos una pequeña muestra de escucha de tres informes autobiográficos que muestran la relación afectiva en el proceso de formación de lectura de los escritores Manuel Bandeira, José Saramago y Cristóvão Tezza.

\section{Lectura Escritores. Autobiografía Escucha.}

Nos últimos 8 anos, nosso grupo de pesquisadores, formado por estudantes de Iniciação Científica, Mestrado e Doutorado, temos nos dedicado à investigação do fenômeno da leitura e das implicações da subjetividade na formação do leitor. Embora reconheçamos as contribuições fundamentais dos estudos do letramento, das pesquisas cognitivistas, da análise do discurso, entre outros, nossa perspectiva tem sido contemplar o fenômeno e suas realizações a partir dos vínculos entre subjetividade e linguagem. Vale dizer, portanto, que consideramos a linguagem, em suas diversas manifestações, como expressão da subjetividade. Nesse sentido, nossos estudos têm se dedicado a abordar um 
campo pouco explorado - até porque de difícil reconhecimento de sua materialidade -, que são as relações entre subjetividade, inconsciente e linguagem.

A leitura, enquanto fenômeno orientado pelas relações simbólicas - seja lá qual for o objeto que se dê a ler -, existe e insiste tão somente porque se trata de um fenômeno em que o sujeito comparece. Não há leitura sem leitor. $E$, muito embora algumas correntes de estudo insistam em conceber o leitor como entidade abstrata e genérica, cada evento de leitura é único tanto quanto seu leitor, ainda que se trate de um mesmo texto enunciado num mesmo tempo.

Buscando compreender a leitura e o leitor mais a fundo, orientamos nossos estudos em três projetos ao longo dos últimos 8 anos, sendo dois deles de pesquisa e um de extensão. Todos eles abordam a leitura e o leitor dentro de uma perspectiva analítica que tem como ponto de partida as relações entre inconsciente e linguagem, amplamente abordadas em trabalhos oriundos da psicanálise freudo-lacaniana. Nessa linha e nos trabalhos de alguns de seus seguidores - como é o caso de Petit e Pennac, temos encontrado suporte para nossas reflexões a respeito de como se opera o fenômeno da leitura e de que maneira ou em que dimensão a subjetividade nela implicada é fator preponderante para situações expressas em derivas e desvios interpretativos, vinculações, aversões, compromissos, medos, entre outros fenômenos que expressam os afetos proporcionados pela e na leitura.

$\mathrm{E}$, mesmo que os afetos estejam presentes em todas as situações de interação como parte constitutiva do encontro do eu com um outro, seja na mais prosaica ou na mais complexa atividade enunciativa, temos nos dedicado principalmente a abordar o fenômeno da leitura e os leitores no espaço-tempo da literatura. Não descartamos, é claro, que as relações subjetivas se deem em qualquer situação de leitura, entretanto, talvez essas expressões do inconsciente sejam mais facilmente tangíveis quando se manifestam dentro de uma ambiência que se propõe a tocá-las diretamente, como é o caso das mais diversas expressões artísticas, incluindo a literatura.

Para compreendermos melhor os propósitos que nos levam a pesquisar os leitores experientes, é preciso fazer uma breve rememoração dos projetos que vimos desenvolvendo em nosso grupo de pesquisa na UEL.

Nosso primeiro projeto de pesquisa realizado na UEL procurou observar as possibilidades de instauração do processo de formação do leitor de literatura desde os primeiros anos do Ensino Fundamental, co-incidindo o prazer da leitura com o entusiasmo no desenvolvimento da autonomia leitora, durante o processo de alfabetização. Deste modo, entre os anos de 2012 e 2015, trabalhamos na compreensão do jovem leitor em formação, sobretudo as crianças que estão nas classes de $1^{\circ}$ ao $3^{\circ}$ ano do Ensino Fundamental. Procuramos observar, então, se era possível ler literatura com as crianças, ajudando-as a estabelecer 
procedimentos autônomos de interpretação ou de apropriação do texto literário, tendo em vista principalmente a possibilidade (talvez a autorização para) de dar à sua leitura contornos próprios, vinculados às suas experiências subjetivas.

Após a finalização desse projeto, verificamos que as condições humanas - isto é, a predisposição dos professores e das crianças envolvidas em nossa proposta - existiam. Entretanto, há desafios a serem enfrentados em termos de sistema de ensino. Vimos que, embora haja disposição dos professores e das crianças para levarem a leitura enquanto atividade regulada pela subjetividade, o tempo-espaço da escola, muitas vezes, não favorece tal abordagem. É preciso ser valente, talvez desobediente para levar a cabo uma proposta de leitura que se esparrame pelo campo do desejo.

Outro projeto de pesquisa a que nos dedicamos foi direcionado para a observação das possibilidades de trabalho com a leitura em que a subjetividade ou simplesmente a individualidade do leitor possa ser considerada como constitutivo da formação leitora do aluno. Para tanto, frequentamos algumas aulas de língua portuguesa de sexto e do sétimo anos e analisamos os livros didáticos nelas utilizados. Pudemos observar o exíguo espaço para a leitura em seu sentido pleno nas nossas salas de aula. Concluímos, então, que, num lugar em que a própria leitura não é permitida, na medida em que se deve garantir o andamento da "matéria" (vale dizer, preenchimento do livro didático e cumprimento de um imenso roteiro gramatical), pouco espaço haverá para o leitor, já que pouco espaço há para o humano, seja ele professor ou aluno. Infelizmente, temos visto que a última instância de interesse em nosso sistema de ensino tem sido o aluno enquanto sujeito desejante.

Concomitante a este último projeto, iniciamos um trabalho, no âmbito da extensão universitária, em que procuramos levar a leitura a crianças e adolescentes de um abrigo judicial de Londrina. Tal experiência revelou muito sobre o fenômeno da leitura e suas relações com a subjetividade, aprendizagem esta que vem fundamentar ainda mais nossa perspectiva de levar à escola a urgência de considerar a subjetividade e o desejo como elementos fundamentais para a formação de leitores.

Desse percurso de investigação e atuação social surge a pesquisa "Escutar o leitor: leitura e subjetividade em biografias e depoimentos de escritores", configurada a partir de algumas leituras de textos autobiográficos e da consideração que Petit (2009) faz a respeito da necessidade de dedicarmos atenção às narrativas de sucesso nos processos de formação leitora.

Nossa intenção com o projeto não é apenas admirar os percursos leitores daqueles que, ao longo desse processo, passaram a dominar tão bem a linguagem escrita e literária, que chegaram a se tornar eles também produtores de literatura. Na verdade, essa tarefa os próprios relatos dos autores por nós elencados já cumprem. 
Ocorre que, ao ler tais relatos autobiográficos de diversos escritores, das mais variadas épocas e locais, observamos que é muito frequente 0 comparecimento de situações em que o livro, a leitura ou a literatura exercem um papel definidor nas vidas de tais sujeitos. A inclusão de passagens de suas vidas associadas à leitura corrobora a afirmação de Petit (2002, p. 58) de que "c'est notre histoire que nous voyons défiler au long des rayonnages." 2 . Para a estudiosa da leitura e dos efeitos desta sobre os leitores, nossas escolhas de livros, de obras, indicam uma forte relação entre $o$ ato de ler e as formações subjetivas, inconscientes por excelência. Admitimos que, do mesmo modo, nossas recusas, marcadas por ausências nas mesmas prateleiras, também são indicativos de espaços não nomeados, a serem descobertos e recobertos; dados também de uma subjetividade em elaboração.

A percepção desse fenômeno - isto é, da vinculação entre eventos biográficos e escolhas de leitura - enquanto constitutivo da própria formação leitora é o que nos impulsiona a melhor compreendê-lo e, talvez, partir para a proposição de abordagens mais eficazes na tarefa de formar leitores na escola. Isto é, estamos convencidos, já desde nossas pesquisas iniciais, que a leitura é uma atividade de ordem subjetiva, absolutamente demarcada pelo afeto, qualquer que seja ele. Ler instaura processos inconscientes que nos permitem vinculações diversas com o que lemos e do que lemos com nossas vidas. A expressão desses processos se opera de diversas maneiras: na leitura absorta, no cuidado com certos volumes (às vezes nos recusamos a emprestar determinados livros), na memorização de trechos inteiros de textos, na busca incansável pela leitura de um mesmo autor, um mesmo estilo, um mesmo gênero, um mesmo conteúdo, enfim. Os relatos autobiográficos são apenas mais uma dessas expressões. Entretanto, do mesmo modo que as outras, demandam uma cuidadosa percepção dos seus sinais. Uma escuta à maneira psicanalítica. Isto é, não são os fatos em si, mas os conteúdos produzidos por meio da linguagem, instada fortemente por processos de ordem inconsciente (LACAN, 1998), que interessam à nossa pesquisa. Nosso trabalho, na sua atividade analítica, reivindica, portanto, o conceito de "escuta" como base do processo de observação e construção de sentidos oriundos das narrativas pesquisadas, tanto escritas quanto orais.

Esse conceito de escuta tem sido também operacionalizado no campo dos estudos sobre mediação da leitura. A pesquisadora Cecilia Bajour (2014) afirma a relevância do processo de escuta na atividade de mediação da leitura, no momento em que se produzem os sentidos ou se abrem os hiatos de significação aos leitores em atividade. Para ela

${ }^{2}$ É nossa história que vemos desfilar ao longo das prateleiras. (tradução nossa) 
El lenguage estético se ofrece a los lectores que se acomodan e incomodan ante maneras alternativas, diversas y a veces transgresoras de nombrar el mundo. Lo que importa allí no es sólo lo que nos sacude nuestras valoraciones, ideas 0 experiencias de vida sino cómo lo hace ${ }^{3}$. (BAJOUR, 2014, p. 13).

Trata-se, portanto, de reconhecer os processos mais refinados, singulares e subjetivos da leitura em curso por meio da escuta, ou, nas palavras da autora de "oír entre líneas", isto é, captar não os preenchimentos, mas os vazios, os intervalos.

Aproveitamos suas considerações sobre a escuta dos eventos de leitura em ato e as ampliamos para um processo investigativo maior, que busca sentidos e afetos nas construções narrativas das biografias de leitores. $O$ processo de recuperação dos traços de memória, dos eventos aos quais dão relevância, o campo semântico que manipulam para compor sua narrativa, toda matéria linguística que operam na busca de um significante capaz de envolver a experiência vivida no percurso de formação enquanto leitores, tornam-se objetos da escuta que propomos. Esse "como" a que se refere Bajour deverá ser não só da ordem do significado, mas da expressão, do significante, muitas vezes, das pausas, dos silêncios, dos não-ditos.

Aprofundar-se nessas histórias, escutar esses leitores pode trazer luzes ao que é viável ser ressignificado na escola, nos modos de escutar os jovens leitores iniciantes, de perceber como a leitura os atinge, quando os atinge, e buscar em tais experiências o reconhecimento da própria narrativa de leitor como marco fundamental para formar leitores na escola. Investigar as narrativas de leitores experientes passa a fazer sentido também no que configura a propagação de discursos que favoreçam um olhar mais desejoso em relação à leitura enquanto atividade relevante social e individualmente.

A exemplo do que estamos aqui defendendo, apresentamos duas narrativas de leitores-autores a partir das quais procuramos realizar esse processo de "escuta". Ao final, arriscamos uma terceira análise a partir de um depoimento de um escritor brasileiro, proferido em uma palestra realizada em Londrina no início de 2018.

Comecemos pelos mortos, ou pelos que se eternizaram em suas obras. Manuel Bandeira, em Itinerário de Pasárgada, obra de 1954, dedica-se a fazer uma reflexão a respeito de sua formação enquanto poeta. Trata-se, portanto, de uma mescla entre biografia e profissão de fé, ou seja, ao mesmo tempo em que relata as experiências que o levaram a uma determinada escrita, reafirma suas

\footnotetext{
${ }^{3} \mathrm{~A}$ linguagem estética se oferece aos leitores que se acomodam e incomodam diante das maneiras alternativas, diversas e às vezes transgressoras de nomear o mundo. O que importa ali não é só o que sacode nossos valores, ideias ou experiências de vida senão como o faz. (tradução nossa)
} 
escolhas poéticas e - por que não? - de vida; vida esta marcada pela poesia e pela morte iminente. Vejamos dois pequenos trechos que nos parecem bastante significativos e que expressam a vinculação do poeta com a leitura, em sua diversa manifestação:

O meu primeiro contato com a poesia sob a forma de versos terá sido provavelmente em contos de fadas, em histórias da carochinha. No Recife, depois dos seis anos. Pelo menos me lembro nitidamente do sobrosso que me causava a cantiga da menina enterrada viva no conto "A madrasta" [...]. (BANDEIRA, 1984, p. 18).

No trecho, Bandeira refere-se à história da menina cujo pai viúvo casa-se com uma mulher muito má, a qual, numa ausência do marido, enterra a menina viva no quintal da casa. No lugar onde a menina fora enterrada, cresce um matagal que, misteriosamente, a cada vez que é cortado, cresce novamente e invade todo o terreno. A narrativa é também conhecida pela canção que o jardineiro ouve cada vez que corta o mato e que diz: "Jardineiro de meu pai/ não me corte os cabelos/ Minha mãe me penteava/ minha madrasta me enterrou./ Pelos figos da figueira/ que o passarinho comeu/ Xô, passarinho, da figueira de meu pai."

Ao narrar sua relação afetiva com a história, Bandeira, mais adiante, reitera: "Era assim que me recitavam os versos. E esse "Xô, passarinho!" me cortava o coração, me dava vontade de chorar". (BANDEIRA, 1984, p. 18).

Conforme é possível notar, os excertos se referem a um momento em que o poeta tinha seu contato com a literatura muito vinculado à transmissão oral. Entretanto, devemos considerar que a apropriação que relata ter feito dos trechos, ainda enquanto criança, denotam uma relação com o texto típica da leitura, na medida em que isola partes, palavras, expressões, tal qual o faria numa apreensão da palavra impressa.

Considerando os dois excertos, observa-se, no primeiro, o uso de uma palavra pouco usual, mesmo na década de 1950 e entre os intelectuais. Tratase do substantivo masculino abstrato "sobrosso". Etimologicamente, o vocábulo está presente na língua portuguesa, ao menos, desde o século III, mas o sentido de "medo, receio, temor", conforme se observa no texto de Bandeira, consta ser próprio de um uso específico dos falares do nordeste brasileiro, em épocas passadas. Segundo o dicionário Caldas Aulete, também é possível associar "sobrosso" a "sobreosso", cujo significado é "excrescência anormal dos ossos que se manifesta à vista e ao tato como elevação ou engrossamento duro e dá lugar a manqueira mais ou menos sensível e permanente ».

A questão aqui é : por que não dizer medo, temor, receio, mas sim «sobrosso »? Esse vocábulo que remete às sonoridades da infância do poeta 
e a imagens terrificantes (os ossos que se deformam) seria a chave para a escuta de algo que se encontra na raiz de todo processo de formação leitora : o medo, a dor, o sofrimento são fortes elementos que nos enlaçam no processo de instauração da formação leitora. Ausente o « sobrosso », teria sido possível a nós percebermos a experiência do poeta como algo tão marcante?

O « sobrosso », vocábulo estranho a nós e também aos leitores cariocas de meados do século XX, nos reporta à infância do poeta, em Recife, em meio às canções e falas dos mais velhos. Resgata uma memória de sons e imagens difusos. Talvez, ali, alguém tenha dito «sobrosso »: três ós fechados, cavernosos, as sibilantes abrindo e fechando a palavra, o encontro consonantal na sílaba tônica (bro), tudo remetendo a um jeito grave de dizer o medo. Tudo convergindo para uma grave seriedade, para o fato de que poesia é coisa muito séria. A ponto de virar motivo de profissão.

A leitura, expressa nessa memória, nessa palavra estranha a compor 0 relato de Bandeira possibilitou esta escuta, aqui articulada também quase como uma nova criação poética, mas que, de todo modo, evidencia algo fundamental : leitura, já desde a oralidade, é qualquer coisa séria e refinada, capaz de « cortar o coração » a partir de um só verso : «Xô, passarinho ! »

Nesse ponto, colocamo-nos o seguinte questionamento : o quanto as crianças que ingressam na escola - ainda não alfabetizadas - já fazem suas próprias leituras, com certo refinamento ? O quanto não nos atentamos para isso porque estamos muito ocupados em impor nossas próprias leituras?

Passemos ao nosso segundo exemplo : a biografia do escritor português José Saramago que, como sabemos, teve uma infância bastante humilde. Seus pais eram analfabetos, e o pouco contato que relata ter tido com livros e jornais quando criança se deu por meio de amigos e vizinhos. Em seu livro As pequenas memórias, Saramago faz um relato poético e, em certa medida, irônico sobre o percurso de sua família, desde a origem na cidade de Santarém até os bairros antigos de Lisboa, passando também pela vida rural em Azinhaga, onde nasceu. Seu relato se aprofunda nas experiências vividas pela família, as faltas, as frustrações, as contantes mudanças de endreço, a escola, a Guerra Civil espanhola, enfim, todos os acontecimentos da infância e juventude do autor que, de alguma maneira, constituem o tecido de sua poética.

Três relatos relacionados às incomuns experiências de leitura na infância chamam a atenção nesse texto de Saramago para nossa pesquisa. Apresentamo-los aqui de forma resumida, em breves paráfrases, mas nos deteremos a um deles.

Como dissemos, Saramago relata três situações em que a leitura se fez marcante em sua biografia. A primeiro delas refere-se às sessões de leitura que a vizinha fazia de um folhetim «água-com-açúcar » e que tinha Sarmago e sua mãe como fiéis ouvintes. A segunda, ainda em fase de alfabetização, quando 
vive a experiência da leitura do jornal que o pai ganhava de alguém no trabalho e o levava para casa. $E$, por fim, sua leitura do teatro de Molière, levado às suas mãos por obra do acaso. Sobre a experiência com a leitura do jornal em casa, Saramago narra:

[...] mal sabendo ainda soletrar, já lia, sem perceber que estava lendo. Identificar na escrita do jornal uma palavra que eu conhecesse era como encontrar um marco na estrada a dizerme que ia bem, que seguia na boa direção. E foi assim, desta maneira invulgar, Diário após Diário, mês após mês, fazendo de conta que não ouvia as piadas dos adultos da casa, que se divertiam por estar eu a olhar para o jornal como se fosse um muro, que a minha boa hora de os deixar sem fala chegou, quando, um dia, de um fôlego, li em voz alta, sem titubear, nervoso mas triunfante, umas quantas linhas seguidas. (SARAMAGO, 2014, p. 86).

Observa-se no trecho a relação tensa do menino Saramago com os adultos que o cercavam, boa parte deles analfabeta e, talvez por essa razão, descrente ou ressentida da possibilidade de uma criança leitora naquele ambiente. Os termos usados pelo autor revelam essa tensão e mesmo a contradição que o momento expressava - afinal, ao fazer sua leitura, estava "nervoso mas triunfante". Mais ainda, seu corpo comparece também intenso - já que a leitura foi "de um só fôlego" - e entra em embate com os dos adultos uma vez que os deixa "sem fala".

Saramago, em sua narrativa, revela um momento de quase sublimação, segundo o conceito psicanalítico. Seu prazer em ler relacionava-se, certamente, com a percepção consciente de que "seguia na boa direção". Mas o prazer experimentado pelo reconhecimento dos outros sobre o valor de sua capacidade parece-nos ainda mais significativo para sua decisão de prosseguir, de buscar novos movimentos nessa "boa direção".

Para a psicanálise freudiana, a tensão entre vida e morte, entre a busca do prazer e a frustração por nunca se atingir a plenitude original, é o que move o regime das pulsões. Nesse regime, a sublimação caracteriza-se por uma realização que sintetiza a busca, atingindo um grau máximo, por isso, considerada por Lacan (1997, p. 141) como o encontro com algo que "tem a dignidade da coisa", isto é, que tangencia uma efetiva nomeação daquilo que nunca se atinge - satisfação primordial e mítica - , mas que, em seguida, já pode ser descartada, porque, apesar de "ter a dignidade da coisa" não é a Coisa, objeto perdido.

O que busca a criança Saramago com a leitura do jornal não saberemos. O fato é que, ao atingir certo alvo - no caso o encontro com algo conhecido, a "boa direção - sente-se instado a compartilhar sua vitória com os demais, ir a 
público, por meio de uma performance leitora, com a qual obtém o reconhecimento tão caro ao processo da sublimação. Isto é, para a criança, naquele momento, não bastou estar na boa direção, saber-se leitor. Era preciso ser visto como leitor, ser admirado por, afinal, ter transposto "o muro", o mesmo que, até então, os críticos adultos não haviam ainda ousado ultrapassar.

Nesse ponto, há que se questionar: quais são os momentos em que, na escola, nossos alunos têm sua expertise reconhecida socialmente? Quando suas leituras são valoradas por serem conquistas suas, não apenas na fase de alfabetização, mas também nos momentos em que se colocam como sujeitos da leitura?

Encerramos esta reflexão com um comentário sobre uma biografia leitora não escrita nem publicada, mas realizada numa palestra proferida pelo professor e escritor Cristóvão Tezza, em Londrina, por ocasião do Londrix (Festival Literário de Londrina), no início de 2018. O tema da fala era justamente a formação do leitor Cristóvão Tezza e talvez o propósito dos organizadores do evento fosse abordar as leituras que os escritores fazem. Na ocasião, ao testemunharmos o relato do autor sobre suas memórias da infância e da juventude e relacioná-las às leituras feitas, alguns enunciados e certos vazios chamaram muito nossa atenção.

Comecemos abordando os vazios. Tezza iniciou seu relato com uma imagem, comparando sua infância com a da Turma da Mônica, isto é, uma comunidade pequena, com crianças que brincam na rua, famílias tradicionais pai, mãe, filho e animal de estimação - etc., e, de saída, já revelou como a leitura dos gibis se impôs em sua vida como modo infantil de nomear o mundo. Pareceu mesmo ter planejado (talvez tenha feito isso mesmo) esse encontro entre forma e expressão a partir da imagem dos gibis para relatar sua infância leitora com mais convicção. $O$ autor prosseguiu a narrativa revelando fatos de sua adolescência, a juventude, a escola, o período em que serviu na marinha mercante, os tempos em que perambulou pelo país com uma companhia de teatro, os anos de chumbo, tudo muito marcadamente circundado por leituras, as mais diversas: Lobato, Verne, Doyle, Conrad, Cortázar. Ao entrar na fase adulta, na vivência universitária, curiosamente, cessa a lista de autores e passa a falar das agruras de ser professor no curso de Letras, da impossibilidade de ensinar literatura, visto que, conforme enunciados do próprio Tezza na palestra, "O professor não pode chorar" e "A literatura tem que ficar num quarto escuro".

Chamou a atenção, naquele momento, a postura tão cuidadosa em relação à literatura, reservando-a para si, para os momentos de absoluta intimidade, e distanciada dos ofensivos espinhos do trabalho acadêmico. Entretanto, mais nos surpreendeu nesse ponto da palestra a interrupção da narrativa do percurso de formação leitora, tão logo o escritor passou a enunciar fatos de um passado mais próximo, quase o seu presente. Não acreditamos que 
Tezza tenha parado de ler quando adulto. Não acreditamos que a literatura e a leitura tenham deixado de fazer efeito sobre ele, de contornar suas experiências, de nomear suas angústias. Parece-nos, talvez, que, mesmo ao mais experiente dos leitores - aos professores, ao escritor -, a leitura em processo, sobretudo as mais significativas, é algo que se coloca naquele quarto escuro, em nós, no inconsciente. Anos depois, tal qual numa sessão de análise, somos capazes de retomá-la, reconhecê-la em nossa experiência subjetiva, sabê-la parte de nós. E isso nos faz considerar que, talvez, alguns silêncios de nossos alunos sobre textos que leem não podem ser imediatamente tomados como incompreensão, não leitura, negação, mas tão somente como a expressão de certo afeto, ainda em processo de nomeação. Mais ainda, é preciso considerar que a leitura não termina quando finalizado o texto. Os processos afetivos e mesmo cognitivos que envolvem a interação com os enunciados são mais extensos que o tempo da própria enunciação.

Corroborando essa concepção, isto é, de que a leitura se constitui enquanto fenômeno fortemente vinculado à subjetividade e ao desejo, Tezza, ao final de sua palestra, fez uma afirmação significativa: "Inventei a mim mesmo através da leitura e da escrita. Inventei quem sou.". Isto é, as leituras, a literatura, são insistentes tentativas de inscrever-se, nomeando o inominável, reinventando aquela porção perturbadora de nós mesmos, aquela que nos escapa e nos denuncia a todo momento, e que tentamos conter, contornar, dar formatos mais belos ou aceitáveis pela linguagem. A leitura pode ser esse apaziguamento momentâneo, intervalo de satisfação do desejo incontido de nossos transbordamentos; a leitura que, segundo Barthes (2010), é hemorragia, é atividade criativa de sentidos e de sujeitos.

É beirando essa orla do desejo e da subjetividade, expressa nas autobiografias de escritores, que temos buscado, em nosso projeto, compreender as vinculações entre desejo, subjetividade e leitura. A partir disso, temos buscado refletir a respeito dos eventos que avançam as margens do desejo e redesenham uma cartografia do sujeito.

Compreender esses processos tão sutis que envolvem a leitura a as formações subjetivas, acreditamos, pode nos levar a repensar as práticas de ensino e abordagens da leitura na escola. Escutar nos silêncios, entrever nas frestas os vazios, perceber o leitor que há de vir e ajudá-lo a tomar os impulsos necessários para isso é tarefa difícil, mas necessária. Nosso maior desejo é saber conduzi-la.

\section{REFERÊNCIAS}

BAJOUR, Cecilia. Oír entre líneas: El valor de la escucha en las prácticas de lectura. Ciudad Autónoma de Buenos Aires: El Hacedor, 2014. 
BANDEIRA, M. Itinerário de Pasárgada. Rio de Janeiro: Nova Fronteira, 1984.

BARTHES, R. O rumor da língua. Tradução de Mario Laranjeira. São Paulo: Martins Fontes, 2004.

FREUD, Sigmund. O mal-estar na civilização. Trad. José Octavio de Aguiar Abreu. Rio de Janeiro: Imago, 1997.

LACAN, Jacques. O seminário, livro 7: a ética na psicanálise. Texto estabelecido por Jacques Alain-Miller / Trad. Antônio Quinet. Rio de Janeiro: Zahar, 1997.

LACAN, Jacques. Além do princípio do prazer. Trad. Christiano Monteiro Oiticica. Rio de Janeiro: Imago, 2003.

PETIT, Michele. Éloge de la lecture: la construction de soi. Paris: Belin, 2002.

ROUXEL, A.; LANGLADE, G.; REZENDE, N. Leitura e subjetividade e ensino de literatura. Trad. Amaury C. Moraes. São Paulo: Alameda, 2013.

SARAMAGO, José. As pequenas memórias. Lisboa: Porto, 2014. 